\title{
Inter-subjectivity and Worker Self-disclosure in Professional Relationships with Young People: A Psychosocial Study of Youth Violence and Desistance
}

\begin{abstract}
This paper argues that psychosocial theory can enhance understanding of intersubjective dynamics between workers and young people involved in crime and violence. After introducing some conceptual tools from psychoanalysis and post-structural theory, a case study follows a worker's efforts to bring about a young man's desistance (including the worker's use of self-disclosure) and how this is stymied by systemic failings in a homeless hostel in the UK. The article concludes that professional work in services targeted at young people with multiple support needs requires a deep sensibility to intersubjective and unconscious dynamics within professional relationships and organisations.
\end{abstract}

Key words: desistance, inter-subjectivity, psychosocial, self-disclosure, young people, youth violence.

\section{Introduction}

This paper draws on psychosocial theory to drill down into relationships between young people and youth professionals, arguing for a need to broaden the base of traditional understandings of such relationships to sufficiently account for psychodynamic intersubjective processes. It incorporates a theorisation of the worker/young person relationship as a fully intersubjective field; a system of ongoing, reciprocal, but not always symmetrical influence where worker and young person negotiate the meanings and subject positions that are created between them. I illustrate how professional engagement with young people exhibiting violent behaviour (especially when that behaviour is rooted in experiences of maltreatment, loss and fractured attachments) may need to incorporate a deeper sensibility to relational psychodynamic processes. I argue that such a sensibility can strengthen the desistance promoting potential of some professional practices, such as the reflexive use of 'self' in the shape of worker self-disclosure.

To begin with, I discuss issues of boundaries and self-disclosure in professional relationships. I then introduce a psychosocial perspective on inter-subjectivity and organisational defensiveness, arguing this provides an apposite framework for work with young offenders. A detailed dyadic case study then follows a young person - a care-leaver (Daniel) with a history of maltreatment and abuse - and his worker (Jim), charting their own biographies and their experience of each-other in a homeless hostel for young people over five months. The story includes Jim's attempts to engender shifts in Daniel's perception of himself and others around him via an approach rooted in dialogical and empathic practice. A psychosocial analysis employs object relations theory to explore the aetiology of Daniel's violent behaviour and then views this in tandem with selected excerpts from Jim's own biographical narrative to plot the processes of inter-subjective recognition (Benjamin, 2004) and masterslave (Lacan, 1977) dynamics that feature within the dyad. I highlight Jim's decision to disclose an aspect of his own biography that renders him more fallible in Daniel's eyes and show how that begins to shift the asymmetry within that dynamic, thereby generating an opportunity for Daniel to construct an alternative, less pervasively violent subjectivity.

However, as the case ultimately unfolds and reveals, this opportunity is quashed by endemic organisational failures within the hostel where Daniel was living. Inept professional practice, inadequate supervision and the dominance of professional discourses that valorise dispassionate, bounded engagement, stymy rather than enable Jim's practice. I argue that these systemic failings and limited practice repertoire of Jim's co-workers represents (if replicated elsewhere) a serious shortcoming in services that purport to look after and 
rehabilitate young people like Daniel, many of whom are in dire need of professional adult support. The paper concludes that workers like Jim might be able to offer meaningful support to young people like Daniel, but if their work is to have maximum desistance promoting potential, youth services and professional development regimes may need to further emphasise understanding of the psychosocial nature of intersubjective dynamics within relationships and organisations.

\section{Professional relationships, boundaries and self-disclosure}

The National Youth Agency ethical code of conduct (2004) states that workers should,

recognise the boundaries between personal and professional life and be aware of the need to balance a caring and supportive relationship with young people with appropriate professional distance (my emphasis) (p6).

How this might translate into practice remains ambiguous; inevitably perhaps, as any evaluation of appropriateness can only ever be meaningfully explored in detailed case studies that provide the necessary contextualization. Merry (1999) argues that workers taking an objective, distant and uninvolved stance can have the effect that young people see workers as only having a professional interest in them; that they are not really concerned about them as individuals with unique life stories. Aron (2013) argues that clients in psychoanalytic therapy often probe their therapists in an attempt to penetrate his/her professional calm and reserve. They do this because they need to connect with others emotionally, "where they are authentic and fully present" (p80). There is some empirical evidence of young people expressing similar views on their relationships with workers. Feaviour and Acres (2000) identified that young people highlight shared experience as a key factor they look for in workers. $* * * * * *$ (author reference) also found that young people involved in violence needed to feel youth workers were willing to show themselves to be fallible as part of mutually trustful relationships. Workers disclosing their own experiences, particularly those that echo young people's, might help facilitate a working alliance (Bordin,1979) with the potential to effect beneficial changes in behavior, such as desistance from crime and violence.

This suggests it might be worthwhile drilling down into the complexity of professional relationships and the use of self-disclosure by workers taking into account intersubjective and unconscious dynamics. Psychosocial approaches to criminality (Gadd and Jefferson, 2007; Jones, 2008) seek to blend psychoanalytic and post-structuralist insights in order to capture how subjects position themselves within a number of competing discourses and the psychological function this serves for them. Adopting such a framework encompasses an acceptance that aspects of the self will always (consciously and unconsciously) be communicated verbally and non-verbally within the intersubjective field of personal and professional relationships. In settings where young people have experienced maltreatment, loss and abuse, this unconscious transmission of unwanted parts of the self, if not contained by another (Bion, 1962) can often be repressed or projected outwards, giving rise to greater challenges for workers seeking to develop productive relationships. What may be required of the worker therefore is to develop a finely tuned understanding of how to use these unconscious inter-subjective dynamics productively and this requires a solid conceptual basis. 


\section{Theorising inter-subjectivity in professional contexts}

The term inter-subjectivity has been used variably within philosophy (Habermas, 1970; Hegel, 1807; Honneth, 1995), symbolic interactionism (Mead, 1934) and psychoanalysis (Benjamin, 2004). For Mead, human self-consciousness derives from the ability to adopt the standpoint of the 'other' toward the self (the 'me' as opposed to 'I'). Benjamin uses the term to emphasise the mutual recognition of subjective mental states in the other as well as in oneself; a relationship in which each person experiences the other as a like subject - another mind who can be felt with, yet has a distinct, separate center of feeling and perception. Benjamin sees the ability to recognize the other in this way as a developmental attainment that begins with the mutual gazing between care-giver and infant and leads to attunement with the other as part of processes of attachment (Bowlby,1958). These early relationships with external others or objects (Klein, 1946) are internalized as internal objects and live on in forms of relating to others in adult life. If the child's environment is one of prolonged instability, neglect and abandonment this can precipitate painful feelings of shame and envy which are then either split off from conscious awareness or manifest later as intense feelings of aggression or paranoia.

Lacan (1977, p58) states that "man's . . . first object of desire is to be recognised by the other". Without intersubjective recognition, human beings have no identity of their own. As Vanheule et al (2003) explain,

Human beings do not so much acquire an identity by assuming certain characteristics but by ascribing characteristics to someone else and positioning themselves with regard to such characteristics (Vanheule et al, 2003, p327).

Following Hegel, Lacan conceptualizes human relations as unavoidably enmeshed within an asymmetrical, master-slave dialectic, by which he means that self-definition is a corollary of the way subjects define others within their experiential field. He suggests a discourse operates within inter-subjectivity that institutes the positions taken up by any two subjects within relationship. Self-consciousness is created through encounter with the other that makes individual subjectivity relative. Subject positions are causally related and characterised by the dominance of one over the other. This can forestall the possibility of change, thereby becoming counter-productive to either party's self-development. It is possible to navigate out of this dialectic - to reconfigure one's sense of self - via a reorientation of the master-slave position. This involves the development of a meta-perspective on the relationship structure itself, so allowing parties to go beyond existing contours. This change of position (and therefore identity) can only be achieved by assigning another place to the other. "The redefinition of the other's identity implies a redefinition of oneself' (Vanheule et al, 2003, p327).

Jean Piaget's staged model of cognitive development (1936) suggests that the reaching of the concrete operations stage at adolescence is an important staging post in the human ability to maintain two perspectives in the mind at once. He suggests that young people begin to look intensely at others around them and make inferences about how they look at them. Conceivably then, the space between young people and workers is one within which young people may come to view the self as subject and object and the other as subject rather than object too, as with Mead's (1934) formulation. Within professional relationships this might involve the young person internalising the worker's image of him/her - a form of reflected appraisal of identity. 
Thus, professional relationships can provide, amongst others in young people's lives, a fertile potential space for interactions that trigger introspection and the building of reflective selfawareness. A psychodynamic conceptualisation of this process would anticipate that much of this interaction may go on unconsciously. Young people's observations of workers might provoke anxiety as they may recognise aspects of the worker that they cannot or do not want to recognise in themselves. At other times, young people may observe aspects that they wish to emulate or notice that they their workers have been moved affectively by them. Young people may need to feel that they have reached the worker in some way and that the worker is different with him/her than they are with other young people.

Post-structuralist thought (Foucault, 1975) has questioned the very existence of unitary identity seeking instead to deconstruct the human subject. This means that the term intersubjectivity would perhaps be better seen as referring to relations amongst multiple identities and voices. The building and development of a young person's identity, a sense of 'I' and 'me', requires therefore the marshalling of these voices into some form of cohesive whole with some continuity along with an ability to tolerate some contradictions too. In order to promote this the worker needs to first develop a coherent sense of his/her own self, reflect upon that self as an object of his/her own investigation and then seek to influence the young person to do the same. One way of achieving this might be the sharing of how they achieved this as part of a process of reflexive self-disclosure. This process becomes especially challenging where worker and young person carry the psychic residue of their own histories of neglect, abuse, trauma or addiction with them into the intersubjective encounter. Moreover, this all occurs within surrounding social discourses (Foucault, 1975) which provide the chalk lines for subject positions and routines that emerge in intersubjective interaction, especially that within 'professional' contexts and across indices of social identity (for example, race, class, gender and age).

Moreover, a professional context such as a hostel providing continuous care for vulnerable young residents could be understood as a social system where often over-stretched staff deploy psychic defences to deal with young people's behaviour and the intensity of young people's feelings, such as aggression, anger, shame, hatred and envy. This will lead to staff experiencing (and then perhaps disavowing) their own intense and sometimes ambivalent emotions, such as fear in the face of aggression or self-doubt as to their capacity to do their job. Menzies Lyth (1960) identifies how these psychosocial processes that occur in such institutions, at both conscious and unconscious levels, can lead to persistent cultures of professional detachment, minimal individual discretion and high staff turnover. These organisational cultures will inevitably affect the quality and nature of intersubjective relationships between workers and young people and therefore their desistance promoting potential.

\section{Methodology}

The following portraits were gathered through a series of Free Association Narrative Interviews (Hollway and Jefferson, 2012). The young person and worker were interviewed separately and emergent findings were used to 'ground' (Glaser and Strauss, 1965) subsequent interviews, allowing for some reframing as the project unfolded. Data analysis was underpinned by the principle of gestalt i.e. the belief that it is impossible to achieve an understanding of structured totals by starting with the ingredient parts which enter into them. Transcripts were read and re-read in conjunction with desistance and psychosocial literature. 
All information gathered during the research process was kept confidential, including that which referred to illegal activities, past or present (unless there was a risk of serious harm or an immediate threat to life). Individual identifiers were removed from stored data. The names of the young person and worker have been changed for the purpose of this article. 'Daniel' and 'Jim' were regularly reminded of the option to withdraw from the research, given contact details of independent support/counselling agencies and provided with a clear complaints procedure.

\section{Daniel}

Daniel, a 22 year-old, white young man, told me he was "born into the wrong type of family"; that he had in fact "never really had a family" at all. His birth parents were related (brother and sister) and he was a product of their incestuous relationship. He had learnt this from reading his personal Social Services file at age 15; an experience he described as like, "sticking a knife in your throat and pulling it out". The records revealed that his birth parents had tried to drown and suffocate him in infancy (probably in a bid to conceal his existence) and as a result of this he had been placed in foster care from the age of 18 months.

He was adopted at age four but felt little emotional connection with his new family or where he was placed, which was, to him, "just another house, just other people." There were plenty of "other people" in the house - ten children in all, six brothers and four sisters, all of whom, according to Daniel, "had their Dads" and "their family". Daniel felt "pushed out", and became a target for ongoing physical and emotional abuse at the hands of his older brothers and sisters, who he later told me still hated him "with a passion". The feeling was mutual; Daniel described his adopted siblings as "boisterous, arrogant twats". He "got on well" with his adopted mother at first, but at age 11 his relationship with her deteriorated. She had told Daniel that she suffered abuse at the hands of her father and this, he felt, had led her to have a "mental breakdown". She began to hit him regularly, sometimes with metal poles, leaving him badly bruised. Sometimes she would lock him in cupboards or tie him to a chair and throw darts at him. On one occasion she had put a knife to his throat. This abuse escalated until it was brought to the attention of Social Services and he was finally removed from the family.

Daniel was sent to a children's home far away from where he had grown up. Other residents would sometimes steal his belongings such as cherished games consoles, mobile phones and clothes, triggering his first outbursts of violent behavior. He felt that the staff in the care homes could not understand his problems as they had "not been through that situation" and were only engaging with him as "professionals" who "finished their job at 5 o'clock" and would then "go home to their families". He remembered lashing out in anger at anybody who tried to help him and deliberately breaking or taking their belongings, especially items that he knew "meant something" to them. At school, his status as a child in care marked him out from his peers and he was relentlessly bullied, "pushed into lockers", "strangled" and "punched". When he became more violent he was eventually moved to another school for young people with similar behavioural issues. From age 11-16 he was moved 148 times between different care homes. This had left him with a sense that all professionals were engaged in a personal vendetta against him and had moved him "for no reason" other than to "save money". He felt his life had been "stunted" within a care system that was "like prison" and had dehumanized him as "just a number in a system". 
The only older man he had ever felt close to was his grandfather. This relationship came to a tragic end when his grandad was violently murdered by two young people that Daniel knew. They were convicted and imprisoned, leaving Daniel, by now 16, devastated at the loss but also desperate for revenge. Feeling like he had nothing left to lose he began to recklessly commit petty crimes such as shoplifting and was regularly involved in fights, often where the odds were heavily stacked against him. He was referred to a psychiatrist but felt the sessions had only made him "worse". He felt the psychiatrist's interpretation of his behavior - that he was "acting out" - was unfair and unduly invasive. Finally, in one session, he grabbed the psychiatrist "by the throat" because "of the stuff he was saying" and he was arrested in the psychiatrist's office.

You sit there, and you open up to a psychiatrist and you say, "I've had this, this, and this, and this." The psychiatrist doesn't understand it in a personal way, but they'll understand in a way, because they're trained to physically understand that kind of stuff, but there is no way you can understand someone who's been through hard times if you haven't been in that situation yourself. Until you've been put in that situation yourself, you'd never have a clue.

His final move before leaving care was to a "really nice house" in a "posh village" where he became friendly with some local young men who invited him back to their homes, but the persistent label of looked-after child led him to experience another crushing rejection; this time from the parents of his new-found friends.

They wouldn't let me near the children. I'd never have friends, could never have friends, because people will automatically judge you for being in care.

Days after his $18^{\text {th }}$ birthday Daniel left the care system and was offered a place in a hostel that he described as a "crack den...not a home, just a place where you put your head". He felt his social workers had "lied" to him as they promised him his own flat if he could prove his ability to cook and manage finances. He admitted he "didn't really know how to stand on his own two feet" but that was because he had not had the "right people" to support him. Unable to cope with life in his new accommodation, Daniel's life went from "bad to worse". He left the hostel and lived on the streets where he met some members of a travelling community who offered him employment and a 15 year-old girl (Tracey) who became his girlfriend. Unable to find accommodation they moved back to Daniel's home town and lived on the streets until they were offered a place in the hostel where they were living at the time we met.

Daniel felt his allocated (female) support worker at the hostel (Mary) was "a waste of time" and "didn't give a shit"; she was "useless", "arrogant", "cocky" and "stuck up her own arse". They had met once in five months even though they were supposed to have weekly meetings and she had not helped with practical things such as organizing a passport for Daniel. She had failed to "read up" on Daniel and suggested that he might seek to make contact with his birth parents. This had "wound" Daniel up, not just because of what she said but "the way she said it". He felt he needed "professional" help but that it needed to be someone who "knew what they were doing".

His relationship with Tracey became increasingly turbulent, including many break-ups. In his final interview Daniel told me that Tracey had fallen pregnant. The prospect of being a father was leading Daniel to feel that he had to "grow up and act like a man".

I am not going to give up on my child like I was given up on. I am not going to turn round and throw my child into the fucking middle of the ocean and let it survive on your own. I am 
going to rear my child how I was supposed to be reared. I am one of them people that will stand up for my child. I will do anything for my child. I want to be able to just do something with my life that is actually meaningful, instead of fucking up all the time.

\section{Jim}

Jim had fond memories of a "decent upbringing" in a "strict" family where financial resources were limited but not "love and care". After leaving school he found work and began to spend his wages "drinking and partying" at weekends. At aged 23 he was involved in a serious violent incident that led to his arrest for attempted murder, although this charge was later dropped for a lesser offence. He was reluctant to disclose the details of the offence, except to say that he was found guilty and spent "some time in prison". He felt the offence had "stuck" with him, but on release, despite his criminal record, he was offered a job at a local car factory. He continued to drink heavily until he was involved in a "nasty" car accident as a passenger, seriously injured and left needing several major operations. The driver (his partner at the time) was pregnant and lost the baby as a result of her injuries. His drinking escalated and he fell into a deep depression.

I was on the bus one morning about 3 months before I stopped drinking with a can of beer, going into town in the morning time. I got off the bus at......for some unknown reason I started walking up the top onto the Express Way and I was gonna jump straight off it....erm...right? Got to the top. My mother normally phones... I speak to my mom nearly every day, and I wasn't at that time in my life... and she phoned my mobile, just at that time...erm....

PH: Just by chance?

Just by chance... and there was no questions asked, there was no....it was gonna happen ... that was it....it was all over... snapped out of it, don't know how... don't know...God knows what. Then the Police come along, took me to the Police station. They were gonna arrest me for trespassing. I had an interview with the Police.... sort of got my thought pattern together.

Jim described this time as "the worst 3 months of my life". Before his first operation he abruptly decided to stop "drinking, smoking and gambling" and began a course of cognitive behavioural therapy.

From that time, I worked on myself. I had to strip myself back to the core. First of all I had to give up alcohol, 'cos that was fuelling the depression, get rid of that, and then the depression was clearer - that's what it was...so I muddled through that and from that day it just kind of fell into place. I sat down I evaluated what's going on in my life, what the positives are, what the negatives are and the positive outweighed the negatives. I looked at the reasons why I was going to do that, the impact on that. I shiver to think about it even today. Then I looked at when I go into work with people, I want to do my best possible and that's it...I've not drunk or smoked for $4 \frac{1}{2}$ years since.

He began to explore other career options and found himself drawn to working with young offenders. He enrolled on a youth and community work training course at a local university and found employment in the homeless hostel where he had met Daniel. 


\section{Intersubjectivity in focus: Daniel and Jim}

Jim described his first meeting and conversation with Daniel as one where Daniel "ranted" and Jim simply listened to him so he could "let off the steam".

[Daniel] turned around and said, "Who the fucking hell are you anyway?". So I said, "Well I'm somebody who's just stood here and listened to you for five minutes, all right?" He went, “Oh, okay, all right then. Well I'm Daniel." So I said, “That's good, I'm Jim. Right, so now we've got past that then. So was that your worst? Or was that your... is there more? Because I'm just starting here".

Jim quickly became a "buffer" between Daniel and other staff at the hostel, who according to Jim could not "handle the aggression" and "handed out warnings left, right and centre". According to Jim, communication between Daniel and the hostel workers (many of whom were temporary staff who spoke English as a second language) was a problem due to "language barriers" and their overly "authoritarian" approach. When Daniel met Jim he felt Jim was different as he intervened in conflicts, remained calm and offered Daniel opportunities to "think outside the box". He could see Jim was frustrated at times, but when he told Jim to "fuck off" Jim would still return and seek to resolve the issue. This made him appear more "human" to Daniel.

He's good; he'll sit there and he'll find a way. He's not generally my support worker but I've had more support off Jim than I have off my own support worker because he understands where I'm coming from. Not only that, he understands I'm 22. In order to get through to me, you've got to speak to me like I'm a 22-year-old. Don't speak to me like I'm a 15-year-old, don't speak to me like I don't know what I'm doing, because I've been there, I've done it.

Daniel felt that some of the incidents in his past would "scare people" but that Jim might be able to understand. The relationship felt more authentic to him than others he had encountered. It was very important to Daniel how Jim looked at him.

Jim looks at you like you're a human. He doesn't look at you like you're a youth; he looks at you like you're just a normal human being that needs help.

Daniel did not share all the details of his past with Jim although he felt that if Jim was allocated to be his support worker he might "open up" to him eventually. Then, on Christmas Eve Daniel showed Jim a SMS he had received from his adoptive brothers with a picture of Christmas presents they had been given and a message gloating that Daniel was not as fortunate. Daniel began to cry within sight of the hostel staff. Jim said they just "tutted" and "sucked their teeth".

I kind of put myself in his shoes within a split second and thought to myself, how would I deal with this? And how can I deal with him as a support worker to kind of diffuse it for him?

Jim saw something in Daniel that reminded him of his own experiences and sensed that Daniel could see this too.

I've got life experiences - somehow he's picked up on that...I could see him getting himself into bother. Sooner or later he's going to do some damage to somebody.

Daniel knew very little "personal" information about Jim because he felt he was not "allowed to know", but he sensed Jim had been through some similar experiences to his own, for 
example that Jim, "wasn't all sweet and innocent as a kid", "probably had his problems", had "struggled in life" and "could look after himself". He felt this was somehow linked to Jim's choice to work with young people.

He's had something happen to him to make him want to do this kind of work, because to do this kind of work it's not one of those things where you think, "I'll do that job." He's been through some of the stuff that we've been through.

Jim initially felt he could not share any details of his own past with Daniel and sought to maintain "solid personal-professional boundaries". He felt a lot of the young people in the hostel had no "father figures" in their lives and was concerned that Daniel may become too "dependent". Jim arranged to bring Daniel into University to meet me, a choice that other staff at the hostel felt was "risky". They doubted Daniel would get out of bed but he was dressed and ready when Jim arranged to pick him up. During the car journey Jim and Daniel discussed Daniel's violent behaviour and the prospect of his ensuing fatherhood. They passed by some of Jim's old drinking haunts and this triggered some nostalgia on Jim's part. He spontaneously said to Daniel,

I tell you one thing, if I hadn't have stopped drinking, I definitely wouldn't be going to University, and I wouldn't be taking you along.

Daniel did not reply, but Jim felt it "got his attention" and that there was a "shift" in Daniel's perception of him and in the dynamic within their relationship.

Jim: I could see the cogs going round .... he was thinking about stuff....it may have brought us down to kind of a level...I'm not this wonderful support worker who knows all; sees all. The way his reaction was, without even saying anything, when he looked at me kind of, it was more of a .... oh right ... ok, so you've got your issues yourself then.

PH You sensed something different?

Yeah, it was more of a .. it was really odd...

PH A non-verbal communication?

Jim: Yeah it was - if he'd said something it would be easier to...but sometimes non-verbal is more powerful than verbal. On the way back he said, "Thanks for taking me out." So I said, "Well, you know, that's okay." And he went, "No, no, in general, because I don't really go anywhere." And when he went back to the $* * * * *$ [hostel] he apologised to the member of staff. He told quite a lot of people that he'd been out, "I've been to the University. I've been to the University today. Guess where I've been? University." It was like Christmas for him.

In his final interview, Daniel felt that he was no longer liable to "throw the first punch" in conflict situations because he was "not that kind of person anymore". He was at pains to draw a distinction between himself and others in the hostel who he felt were "scumbags using the fact that they had been in care to kill someone or to deliberately hurt someone". However, he still had "flashbacks" and "panic attacks", especially if he was ever immersed in water above his waist or in large groups of people. His behavior in the hostel remained unpredictable especially when he felt "threatened" which would sometimes still trigger an "automatic" response. 
Daniel wanted Jim to be his allocated support worker but was told a written request was required and Jim was not allowed to help or encourage Daniel to fill out the form. Before this could be arranged Daniel became involved in an altercation with another resident and was evicted from the hostel. Jim regretted not "pushing" the transfer more.

I think if I'd spent more time with him and done more work on him, it would have been a different outcome. I think with the right guidance and understanding he would have been a different kettle of fish. He would have addressed his anger. I think to just evict him, that was a bad mistake, or a bad outcome.

\section{A psychosocial analysis}

This story provides insight into the complex intersubjective dynamics within evolving relationships between young people and workers in settings such as the homeless hostel where Daniel was living. Daniel's bleak story amounts to an archetypal account of how maltreatment and fractured attachments in childhood can lead to violent behaviour in adolescence, and corroborates findings from other studies (Renn, 2002; or see Cashmore, 2011 for a comprehensive review). His story, including the shocking account of abuse at the hands of a mother suffering with her own mental health issues accounts for his complex, acute needs including the persistent sense of persecution that characterised his relationships in adulthood. His struggle to sustain the tension between his own needs and those around him leads to his needs becoming steadily more pressing and his isolation and erratic behaviour more pronounced. His anxiety when in "water up to his waist" or in "large groups of people" could be interpreted as a result of the trauma he experienced in infancy (notably his birth parents' attempt to drown and suffocate him). The violent abuse at the hands of his adoptive family seems to have left him trapped in a fearful, angry attachment pattern. Gripped within an intensely vulnerable affective state he was adopting a veneer of self-sufficiency to mask and defend against intolerable feelings of terror, shame and envy. Those around him who he felt possessed the 'objects' that he lacked - material possessions, and above all, a family to belong to and a place to call home - became the target of his violence. When his psychic defences failed in the face of rejection or disappointment more paranoid psychic processes emerged including hypervigilance for further signs of shaming or rejection. Real or perceived slights gave rise to him unleashing his anger and hostility on those nearest to him who threatened to harm his fragile state, such as fellow residents or professional staff. His shoplifting and violence is triggered primarily by his need to protect and hold onto his own external objects (e.g. games consoles) or precious internal objects (Klein, 1935), such as his grandfather. His turbulent relationship with his younger and equally vulnerable girlfriend could also be attributed to his inability to cope with unbearable feelings, for example fear that she might hurt or abandon him too.

The focus of this analysis however is less on how Daniel's biographical experience is related to his violent behaviour and more on how it colours his relationships with the many professionals he encounters in the system, and especially Jim. Formulations of professional relationships that emphasise more conscious processes of empathy and dialogue struggle to capture the way in which Daniel, Jim and the other professionals involved are continually negotiating and renegotiating their respective subject positions within surrounding social discourses. His rage at being abandoned, rejected and then failed by everyone in his life, combined with the inadequacies of some inexperienced, demotivated workers mean his relationships with professionals was infused with a deep mistrust. Daniel comes to see first 
his social workers and then the hostel staff adults as persecuting, conspiratorial masters who are responsible for the grave injustices he has suffered. The fact that some of the hostel staff are from socially different backgrounds in terms of race and gender intensifies his split view of them, transforming them from poorly trained (and paid) inadequately supervised people struggling to manage other challenges into starkly negative caricatures. The workers' lack of empathy at times and apparent defensiveness may have been a product of the difficulties they were having diffusing the considerable anxiety triggered as a result of their responsibility for young people in such distress and dire circumstances (Menzies-Lyth, 1960). Daniel's disparaging (gendered?) appraisal of his female support worker and (racialized?) frustration around the language barriers between him and other staff (shared by Jim) shows how social indices of identity can become entangled with psychic processes. His violent assault on his psychiatrist seemed to be driven by this mistrust and his sense of a dispassionate psychic detachment on his/her part. The psychiatrist's (presumably well-intentioned) efforts at interpretation misfire disastrously because of Daniel's defensiveness, but also because the psychiatrist has difficulty communicating with Daniel across a psychic experiential divide. This divide opens up in Daniel's mind because he perceives the psychiatrist to have no experience that mirrors his own. This fissure may well have deepened as a result of Daniel's perception of a difference between him and the psychiatrist in terms of social class too.

Maybe it was easier for Daniel to demonise all these professionals than to grieve the loss or lack of his own personal relationships, such as his family or friends. Notwithstanding the serious deficiencies in the way some of these professionals had treated him, his all or nothing view of workers who would "never have a clue", the prevailing discourse of professional boundaries and the foregrounding of different social identities, leads him to experience his relationships with professionals as framed within a sharply defined master-slave dialectic (Lacan, 1977). He becomes a "number in a system", trapped in a "prison"; "not a person anymore". This self-perception translates into an arresting sense of coercive dependency where he feels done-to, not like an agent helping to shape a co-created reality (Benjamin, 2004).

Jim roots his approach to Daniel in notions of dialogic, empathic practice, mutual respect, authenticity and integrity. His empathy arises in part from his own struggle with the repercussions of having a criminal record, which gives him an understanding of how hard it can be to shake off externally imposed negative labels and stigma. He knows how it feels to suffer from depression and addiction in the form of alcoholism. His own epiphany and desistance, triggered by his accident resulting in the loss of his unborn child and then his drift into depression and close shave with suicide, seems to have left him with a determination and desire to help young people going through similar tribulations. His choice of career allowed him to generatively restore and redeem damaged parts of himself by seeking to help others, although (importantly) he is able to recognise the separateness of Daniel's subjectivity and the differences between their respective childhood experiences. Jim's persona, rooted in his personal experiences and social identity as an older, white, working class man who can "look after himself" seems to have surprised and engaged Daniel. He feels that, unlike other professionals he had encountered, Jim sees him more as an adult and fully "human". The visit to the university allows Daniel to begin to internalise Jim's more positive appraisal of him and the experience is in stark contrast to the pervasive negative labelling he experiences from the other workers. This all allows Daniel to begin to call into being an alternative less destructive subjectivity based in a more affirming standpoint of the generalised other towards himself (Mead, 1934). 
It is far from certain that any worker could have marshalled the disparate voices within Daniel's subjectivity into a more cohesive whole in such a short timescale. However, Jim's impromptu decision to allow Daniel to see his own fallibility by disclosing his struggle with alcohol seems to have eased Daniel's sense that only he was "born in to the wrong type of family". It shows that others can experience internal conflict too and moves Jim from a master subject position in Daniel's mind that could have otherwise left Daniel feeling that Jim owned him and that he had nothing to give back. The prominence of this dynamic within his relationships to other professionals was leading to an impasse. When Jim simply contains (Bion, 1962) Daniel's rage it pulls Daniel up sharply enough for him to ask "who are you?" Not accustomed to Jim's calm acceptance, he begins to see Jim's professional interpretation of his behavior as supportive rather than judgmental and this triggers some introspection. This seems to have led Daniel to seek a different way to regulate his emotional responses. He begins to experience Jim as a like subject; another mind who can be felt with and the pair move beyond a doer and done to (Benjamin, 2017) relational frame. This prompts Daniel to see the need to apologise to another professional in the hostel that he feels he has wronged in the past. If Jim had had the opportunity to express more of his own vulnerabilities by becoming his support worker this might have amplified this new voice within Daniel and created room for Daniel to construct a subjectivity less centred on violence. In the end the frailties of the system induced a recapitulation of Daniel's long list of broken attachments as hostel staff are drawn into his re-enactments of previous relationships and then defensively retreat into impersonal professional identities. Any potential to promote desistance is foreclosed because Daniel is again pushed out; evicted by workers who are unwilling or unable to tolerate his challenging behavior leaving him abandoned to fend for himself once more. The opportunity to explore the underlying reasons for his violent behaviour and continual conflict with professionals is lost. The implications of all this for Daniel, his equally traumatized and damaged partner Tracey, and their unborn child (despite Daniel's resolve to desist and be the kind of father that he never had) are deeply troubling.

Jim's own experiences of beginning to work through his own issues via CBT and his training seem to have built up a degree of reflexivity although he was still carrying the burden of a violent offender label and the loss of his own potential fatherhood. His halting description of his aborted suicide attempt showed that these memories were still imbued with considerable affect and his initial reluctance to talk openly about parts of his biography that threatened to destabilize his new professional identity illustrates the presence of psychic residue from those events, including some regret and shame. These issues needed to be worked through in professional supervision - a resource that was never made available to Jim or any other staff in the hostel. Notwithstanding this, it appears that it was Jim's willingness to share his fallibility (and how this led him and Daniel to fully recognise each-other as subjects) that seemed to generate the most promising route out of the chaos, criminality and violence that had characterised Daniel's life up to that point.

\section{Conclusion}

This case illustrates the potential for desistance promotion that workers like Jim bring to their work with young people who have a history of maltreatment and loss. It shows how, even within limited time frames, empathic professionals who are able to contain young people's emotional affect and defensive projections without retaliating or retreating into their own defensive professional identities can begin to modify violent behaviour. Specifically, it shows how worker reflexive self-disclosure can form part of a meaningful professional response to youth violence. 
Furthermore, it demonstrates the way in which psychosocial theory can be used to explicate offending behaviour, the intersubjective dynamics between young people and workers, and how organisational cultures can quash good practice. Interpersonal relationships form a significant part of professional interventions with young people in many contexts, including criminal justice, education and social care. If replicated elsewhere, the systemic failings highlighted by this case paint a worrying picture of some support services for young people like Daniel. Workers in organisations like the one Jim was working in need training and supervision that incorporates a sensibility to the intersubjective and unconscious dynamics within their relationships and within the institutions in which they are employed. Training in related fields such as social work and probation in the UK, via the CQSW, traditionally included a consideration of psychodynamics (Vanstone, 2004). This single case study adds weight to the case for maintaining an understanding of psychodynamics within worker training, possibly via the adoption of a psychosocial conceptual framework. Daniel and Jim's story illuminates how individual psyches and social discourses shape the identities and practices of young people and adult workers, the intersubjective dynamics between them and within institutions. Understanding this further might in turn increase the likelihood of achieving more positive outcomes for young people like Daniel who are in dire need of competent adult professional support.

\section{References}

Aron, L. (2013) A Meeting of Minds: Mutuality in Psychoanalysis, London: Routledge.

Benjamin, J. (2004) 'Beyond doer and done to: An intersubjective view of thirdness'. Psychoanalytic Quarterly. 1 (Jan) 5-46.

Bion, W. (1962) 'The psychoanalytic study of thinking', International Journal of Psychoanalysis, 43, 306-310.

Bordin, E. (1979) 'The generalizability of the psychoanalytic concept of the working alliance', Psychotherapy: Theory, Research and Practice, 16, 252-260.

Bowlby, J. (1958) 'The nature of the child's tie to his mother'. International Journal of Psychoanalysis, 39, 350-371.

Cashmore, J. (2011) 'The link between child maltreatment and adolescent offending: Systems of neglect of adolescents'. Family Matters, 89, 31-41.

Cooley, C. (1902). Human Nature and the Social Order. New York: Scribner's.

Crozby, P. (1973) ‘Self Disclosure: A Literature Review’, Psychological Bulletin, 79 (2) 73-91.

Feaviour, K. and Acres, D. (2000) 'England: Young People from the South and South West of Britain' in Youth and Coping in Twelve Nations: Surveys of 18-20 Year Old Young People ed. J. Gibson-Cline, Bristol: Routledge.

Gadd, D. and Jefferson, T. (2007) Psychosocial Criminology: An Introduction. London: Sage. 
Habermas, J. (1970) 'Towards a theory of communicative competence'. Inquiry, 13, 360-375

Hegel, G.W.F. (1807) The Phenomenology of Mind. London: George Allen and Unwin Ltd.

Hollway, W. and Jefferson, T. (2012) Doing Qualitative Research Differently. London: Sage.

Honneth, A. (1995) The Struggle for Recognition. The Moral Grammar of Social Conflicts. Cambridge, MA: MIT Press.

Jones, D. (2008) Understanding Criminal Behaviour: Psychosocial Approaches to Criminality, Cullompton: Willan.

Klein, M. (1946) "Notes on Some Schizoid Mechanisms". International Journal of Psychoanalysis, 27:99-110.

Lacan, J. (1977) Ecrits. London: Routledge.

Mead, G.H. (1934) Mind, Self and Society. Chicago: University of Chicago Press.

Menzies Lyth, I. (1960) "A case in the functioning of social systems as a defence against anxiety: a report on a study of the nursing service of a general hospital", Human Relations. 13:95-121.

Merry, T. (1999) Learning and Being in Person Centred Counselling. Herefordshire: PCCS Books.

National Youth Agency. (2004) Ethical Code of Conduct. [online] Available at: http://www.nya.org.uk/wp-content/uploads/2014/06/Ethical_conduct in_Youth-Work.pdf. [Accessed] 8/5/17.

National Youth Agency. (2016) Annual Monitoring Youth and Community Programmes 2014-15 [online] Available at: http://www.nya.org.uk/resource/annual-monitoring-youthcommunity-programmes-2014-15/. [Accessed] 8/5/17.

Piaget, J. (1936) Origins of Intelligence in the Child. London: Routledge and Kegan Paul.

Renn, P. (2002) 'The link between childhood trauma and later violent offending: The application of attachment theory in a probation setting'. Attachment and Human Development. 4 (3) 294-317.

Rosenfeld, L. and Gilbert, J. (1989) 'The Measurement of Cohesion and its Relationship to Dimensions of Self Disclosure in Classroom Settings', Journal of Small Group Behaviour, 20 (3) 291-301.

$* * * * * *$ author reference

Vanheule, P. et al. (2003) "Burnout and Intersubjectivity: A Psychoanalytic study from a Lacanian perspective". Human Relations. 56 (3) 321-338. 
Vanstone, M. (2004) Supervising Offenders in the Community: A History of Probation Theory and Practice. Aldershot: Ashgate. 